\title{
Synthesis, characterization and in vitro cytotoxicity assessment of hydroxyapatite from different bioresources for tissue engineering application
}

\author{
SUDIP MONDAL, RAJASHREE BARDHAN, BISWANATH MONDAL*, APURBA DEY ${ }^{\dagger}$, \\ SUDIT S MUKHOPADHYAY ${ }^{\dagger}$, SYAMAL ROY ${ }^{\ddagger}$, RAJAN GUHA ${ }^{\ddagger}$ and KOUSHIK ROY ${ }^{\ddagger}$ \\ Centre for Advanced Materials Processing, CSIR-Central Mechanical Engineering Research Institute, \\ Durgapur 713 209, India \\ ${ }^{\dagger}$ Department of Biotechnology, National Institute of Technology, Durgapur 713 209, India \\ $¥$ CSIR-Indian Institute of Chemical Biology, Kolkata 700 032, India
}

MS received 3 May 2011; revised 13 October 2011

\begin{abstract}
In the present study, hydroxyapatite (HAp) is synthesized from different biosources like eggshell, fish scale and bovine bone in a cost effective and ecofriendly way. HAp materials were synthesized from eggshell by wet precipitation method whereas thermal decomposition method was applied in case of fish scale and bovine bone. The phase purity and crystallinity of different calcined HAp powder were determined by XRD and FTIR analyses. The thermogravimetric analysis was carried out to show thermal stability of HAp powder. Average grain sizes of sintered samples were in submicron range. The morphology of the powders were observed under scanning electron microscopy (SEM). The dried powders were wet ball milled for several hours and surfactants like Triton-X small fillers (2 / $4 \mathrm{~mm}$ long rod-shaped) were made for in vitro testing. In order to verify the biocompatibility of HAp powders, cytotoxicity evaluation was carried out in RAW macrophage like cell line media for an incubation period of $72 \mathrm{~h}$. The cell attachment studies on HAp compacts show an excellent affinity between cells and compact surface. These results proved high biocompatibility of HAp powders obtained from different biosources for tissue engineering applications.
\end{abstract}

Keywords. Hydroxyapatite; biomaterials; sintering; tissue engineering; cytotoxicity.

\section{Introduction}

Hydroxyapatite and calcium phosphate based materials have attracted considerable interest in the field of tissue engineering because of similarities with the mineral fraction of natural bone and high biocompatibility with living tissues. It has good bio-affinity, stimulates osteo-conduction and is slowly replaced by the host bone after implantation. Application of hydroxyapatite biomaterial as a porous or granulated material is useful in bone surgery or coating on metallic bio-implants. A number of methods have been used for HAp powder synthesis such as solid state reaction, hydrothermal reaction, co-precipitation reaction, sol-gel synthesis, mechano chemical synthesis, etc (Kim et al 2000; Balamurugan et al 2002; Tadic and Epple 2003; Mobasherpour et al 2007; Parthiban et al 2009).

The present study illustrates synthesis and processing parameter of HAp powder from egg shell, fish scale and bovine bone. Natural structural HAp material from these biosources (Mondal et al 2010; Bardhan et al 2011) not only provides an abundant source for novel bone and cartilage replacement surgery but it also inspires investigations

\footnotetext{
*Author for correspondence (bnmondal@ rediffmail.com)
}

to develop biomimetic composites. In this study HAp powder was synthesized at low temperature from egg shell by wet precipitation method using nitric acid and di-ammonium hydrogen phosphate. Eggshell is made up by a three-layered structure, viz. the cuticle, the spongeous layer and the lamellar layer. Chemical composition of egg shell crust is calcium carbonate (94\%), magnesium carbonate $(1 \%)$, calcium phosphate $(1 \%)$ and organic matter (4\%) (Prabakaran et al 2005). Eggshell is a good source of calcium carbonate and this source can be utilized for synthesis of hydroxyapatite. Wet precipitation route is quite favourable because of its ease in experimental operations, low working temperature and high percentages of pure products. This study also illustrates the development of hydroxyapatite biomaterial from fish scales. Fish scales are mainly composed of collagen, connective tissue proteins, water and the remaining 41-84\% (Sankar et al 2008) of other proteins. This study shows that the biomimetic property may lead to the development of new biomaterials. There are several types of calcium phosphate salts, which are present in fish scales due to their extreme biological response in physiological environment. HAp powder was extracted by calcining the chemically treated fish scales at different temperatures. Extraction of hydroxyapatite from bovine bone is biologically safe and economic, since it is easy to obtain. Bone is a unique composite, containing 
a collagenous hydrogel matrix consisting of about 33-43\% apatite minerals, 32-44\% organics and 15-25\% (Kalita et al 2007) water on a volumetric basis. HAp material manufactured from bovine bones has the advantage of inheriting some properties of the raw materials viz. its chemical composition and structure. The synthesized powder from these three different biosources is ball milled for several hours and compacted. The synthesized powder and compacted samples were characterized through thermogravimetric analysis, $\mathrm{X}$-ray diffraction (XRD) and Fourier transform infrared spectroscopy (FTIR). The morphology of the derived hydroxyapatite powder and their sintering behaviour has also been studied by FESEM. Many processing technologies have been employed to obtain porous ceramics for bone tissue engineering. In tissue repair application the macro pores and highly interconnected networks are required for growth of surrounding of host tissues. The milled powder was mixed with surfactant and finally press injection method was applied to make small diameter fillers. As a first parameter of biocompatibility (Sandeep et al 2006), the ability of the cells to attach to the material surface during early period of cell/material interaction was used. Then the powders were screened in vitro for cytotoxic (Roy et al 2011) effects on cultured RAW macrophage cells. Cell attachment (Van der Stok et al 2011) study was observed by scanning electron microscopy. Cytotoxicity effects were analysed by Trypan blue staining method.

\section{Experimental}

\subsection{Synthesis of hydroxyapatite powder from egg shell}

Raw egg shells were initially washed with water and then treated with $0.5 \mathrm{~N} \mathrm{HCl}$ (Merck 35\%) to separate the membrane. The egg shell powder was dissolved in dilute nitric acid, $\mathrm{HNO}_{3}$ (Merck, 70\%) by warming the solution. The chemical reaction is given below:

$$
\mathrm{CaCO}_{3}+2 \mathrm{HNO}_{3}=\mathrm{Ca}\left(\mathrm{NO}_{3}\right)_{2}+\mathrm{CO}_{2}+\mathrm{H}_{2} \mathrm{O} .
$$

Then $0.6 \mathrm{M}$ di-ammonium hydrogen phosphate solution was added drop-wise while stirring for $1 \mathrm{~h}$ producing white coloured HAp precipitate. $\mathrm{pH}$ of the reaction was adjusted to 9 by addition of dilute ammonium hydroxide solution. The chemical reaction is given below:

$$
\begin{aligned}
& 10 \mathrm{Ca}\left(\mathrm{NO}_{3}\right)_{2}+6\left(\mathrm{NH}_{4}\right)_{2} \mathrm{H}\left(\mathrm{PO}_{4}\right)+8 \mathrm{NH}_{4} \mathrm{OH} \\
& \quad=\mathrm{Ca}_{10}\left(\mathrm{PO}_{4}\right)_{6}(\mathrm{OH})_{2} \downarrow+20 \mathrm{NH}_{4} \mathrm{NO}_{3}+6 \mathrm{H}_{2} \mathrm{O} .
\end{aligned}
$$

The precipitate was thoroughly washed and filtered. The residue was dried in an hot air oven at $100^{\circ} \mathrm{C}$ for $12 \mathrm{~h}$ and then sintered at $1000^{\circ} \mathrm{C}$.

\subsection{Synthesis of hydroxyapatite powder from fish scale}

Fish scales were collected from fresh water fish (Labeo rohita) and washed thoroughly in running tap water. The collected scales were initially deproteinized through external washing with $1(\mathrm{~N}) \mathrm{HCl}$ (Merck, 35\%) solution (2:1, $\mathrm{v} / \mathrm{w}$, water $\mathrm{HCl} /$ fish scale) for $24 \mathrm{~h}$ at room temperature $\left(28^{\circ} \pm 2{ }^{\circ} \mathrm{C}\right)$. Next the deproteinized fish scales were washed thoroughly several times with distilled water. Remaining proteins of fish scales were treated with $1(\mathrm{~N})$ $\mathrm{NaOH}$ solution. The filtered fish scales were washed thoroughly with distilled water and dried at $60^{\circ} \mathrm{C}$ in hot air oven for several hours. Treated fish scales were calcined at different temperatures to synthesize hydroxyapatite ceramics.

\subsection{Synthesis of hydroxyapatite powder from bovine bone}

Bovine bone were initially deproteinized externally with 1 (N) $\mathrm{HCl}$ (Merck, 35\%) solution and finally $1(\mathrm{~N}) \mathrm{NaOH}$ solution was added for removal of remaining proteins. The samples were then thoroughly washed with double distilled water and dried at $50-60^{\circ} \mathrm{C}$ in an hot air oven. The dried samples were then calcined in air atmosphere for $1 \mathrm{~h}$ at different temperatures viz. $900^{\circ} \mathrm{C}, 1000^{\circ} \mathrm{C}, 1100^{\circ} \mathrm{C}$ and $1200^{\circ} \mathrm{C}$ to obtain HAp phase.

\subsection{Preparation of small fillers}

The synthesized powder was mixed with starch and milled for $48 \mathrm{~h}$ in ball mill. Triton-X surfactant was added dropwise with the powder to make a paste. Injection press method was employed to make small $2 \mathrm{~mm}$ diameter and $4 \mathrm{~mm}$ long fillers with this paste. The small rod shaped fillers were then dried at $80^{\circ} \mathrm{C}$ for several hours. Finally the dried samples were sintered at $1100^{\circ} \mathrm{C}$ for $2 \mathrm{~h}$.

\section{Powder characterization}

Thermogravimetric analysis of HAp from egg shell, treated fish scale and bovine bone was carried out using a Thermal Analyzer (Netzsch, STA 409) over a temperature range of $30-1250^{\circ} \mathrm{C}$ and a heating rate of $10^{\circ} \mathrm{C} / \mathrm{min}$ under air atmosphere. The crystalline phases of synthesized powders were identified by X-ray diffraction analysis (Shimadzu, XRD$6000, \mathrm{CuK} \alpha$ radiation). FTIR (Perkin Elmer) analysis of calcined powder at different temperatures was carried out to confirm the structural composition. The average particle sizes of powder samples were observed through SEM analysis. The optimized calcined hydroxyapatite powder derived from these three different biosources was wet ball milled for several hours and compacted into cylindrical/square shapes. Transmission electron microscopy (TEM) studies were carried out using JEOL-JEM classic modes such as bright field (BF) to image the texture of the materials (shape, dimension). The samples were prepared using ultra-microtomy to obtain thin samples with a thickness inferior to $80 \mathrm{~nm}$. The preparations were deposited on a copper grid covered by a thin film of amorphous carbon. This protocol was used in order to minimize sample artifacts such as amorphization. 
Cytotoxicity and cell attachment studies of synthesized HAp materials were also carried out in RAW macrophage-like cell line media.

\section{Results and discussion}

\subsection{TG DTA analysis}

Thermogravimetric plot for synthesized HAp powder from egg shell is shown in figure 1. HAp materials prepared via low temperature wet-chemical processes are known to accommodate various ionic species like $\mathrm{H}_{3} \mathrm{O}^{+}, \mathrm{HPO}_{4}^{2-}$ and they decompose in a variety of ways. There is around $7.56 \%$ weight loss upon heating up to $300{ }^{\circ} \mathrm{C}$ due to the elimination of weakly entrapped adsorbed water in HAp powder. Weight loss around $3.41 \%$ between $300^{\circ} \mathrm{C}$ and $700^{\circ} \mathrm{C}$ corresponds to $\mathrm{HPO}_{4}^{2-}$ decomposition which may be present in the chemically synthesized powder (Fung 1993). In the range $700-800^{\circ} \mathrm{C}$, weight loss was due to the removal of interstitial water and decomposition of $\mathrm{P}_{2} \mathrm{O}_{7}^{4-}$. However, there was only $0.36 \%$ weight loss on further heating up to $1250{ }^{\circ} \mathrm{C}$. Total mass loss of about $11.33 \%$ was obtained for HAp powder leaving $88.77 \%$ of residual mass. DTA plot shows a broad dip in the range of $300-600{ }^{\circ} \mathrm{C}$ corresponding to the decomposition of $\mathrm{HPO}_{4}^{2-}$. The exothermic peak at a range of $680-810^{\circ} \mathrm{C}$ is associated with complete crystallization of synthesized hydroxyapatite powder.

The thermogravimetric analysis of chemically treated fish scales were carried out between $35^{\circ} \mathrm{C}$ and $1250^{\circ} \mathrm{C}$ in air at a heating rate of $4^{\circ} \mathrm{C} / \mathrm{min}$ as shown in figure 2 . In this analysis actual weight losses (Mortier et al 1989; Ozawa and Suzuki 2002) are observed in three steps and the related temperature range is $30-800^{\circ} \mathrm{C}$. The first loss is due to the weakly entrapped water in the sample material, second and third losses resulted from the decomposition and burning of organic components in the raw scales. As the washing treatment could not completely remove the organic compounds of the inner parts of scale structure, the large weight loss resulted mainly from those organics. However, there was minor weight loss on heating up to $1250^{\circ} \mathrm{C}$ which indicates thermal stability of the sample in this range. DTA plot shows a sharp exothermic peak in the range from $480-800^{\circ} \mathrm{C}$, which is due to the crystallization of synthesized powder.

The thermogravimetric analysis (figure 3) of chemically treated bovine bone was carried out from room temperature to $1250{ }^{\circ} \mathrm{C}$ in air atmosphere at a heating rate of $4{ }^{\circ} \mathrm{C} / \mathrm{min}$. In this analysis actual weight losses were observed with rising temperature. The first loss is due to the removal of trapped water in the sample material, second and third losses resulted from the decomposition and burning of organic components in the bovine bone constituents. However, there was minor weight loss which occurred on heating up to $1250^{\circ} \mathrm{C}$. DTA plot shows a broad exothermic peak in the range from $500-1000{ }^{\circ} \mathrm{C}$, which is due to the crystallization of synthesized powder similar to fish scale derived hydroxyapatite. The endothermic peak around $150^{\circ} \mathrm{C}$ is due to loss of incorporated water and decomposition of organic matter of the bovine bone.

Table 1 shows comparative mass loss study of HAp preparation from three different sources. The first two major weight losses in the ranges of $35-200{ }^{\circ} \mathrm{C}$ and $200-500{ }^{\circ} \mathrm{C}$ were observed in fish scale due to presence of trapped water molecules, organic particles such as connective tissue proteins, collagen etc. In case of egg shell derived HAp powder no such weight loss occurs due to organic materials as it

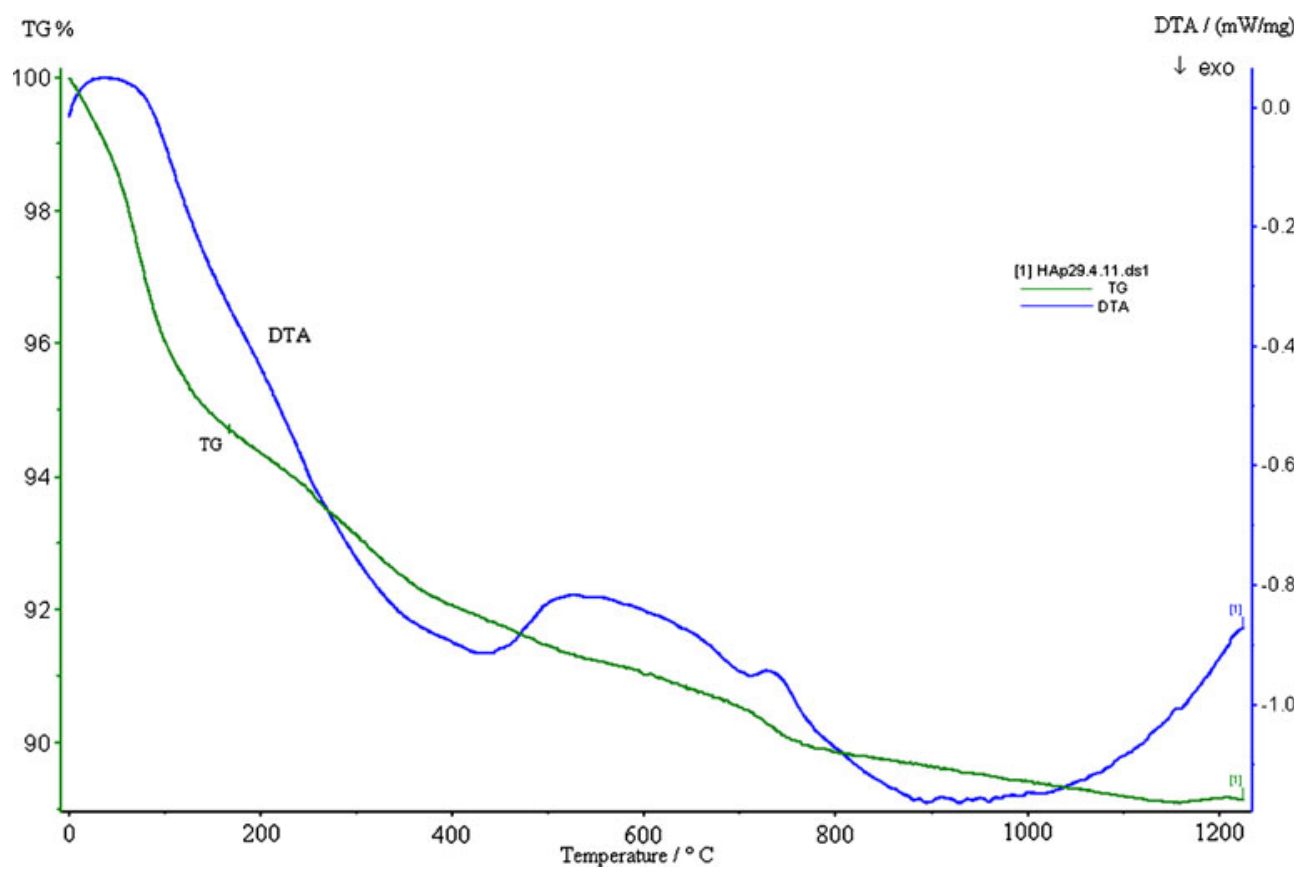

Figure 1. TG DTA of egg shell derived HAp powder. 
is a wet chemical precipitation method where major organic materials are previously removed by chemical treatment. In case of bovine bones the major part of bone is made up of hydroxyapatite materials. For this reason moderate weight loss occurs in respect of the fish scale.

\subsection{XRD analysis}

The crystalline phase analysis of HAp powder from three different biosources was carried out by X-ray diffraction studies. Figure 4 shows XRD pattern of synthesized HAp

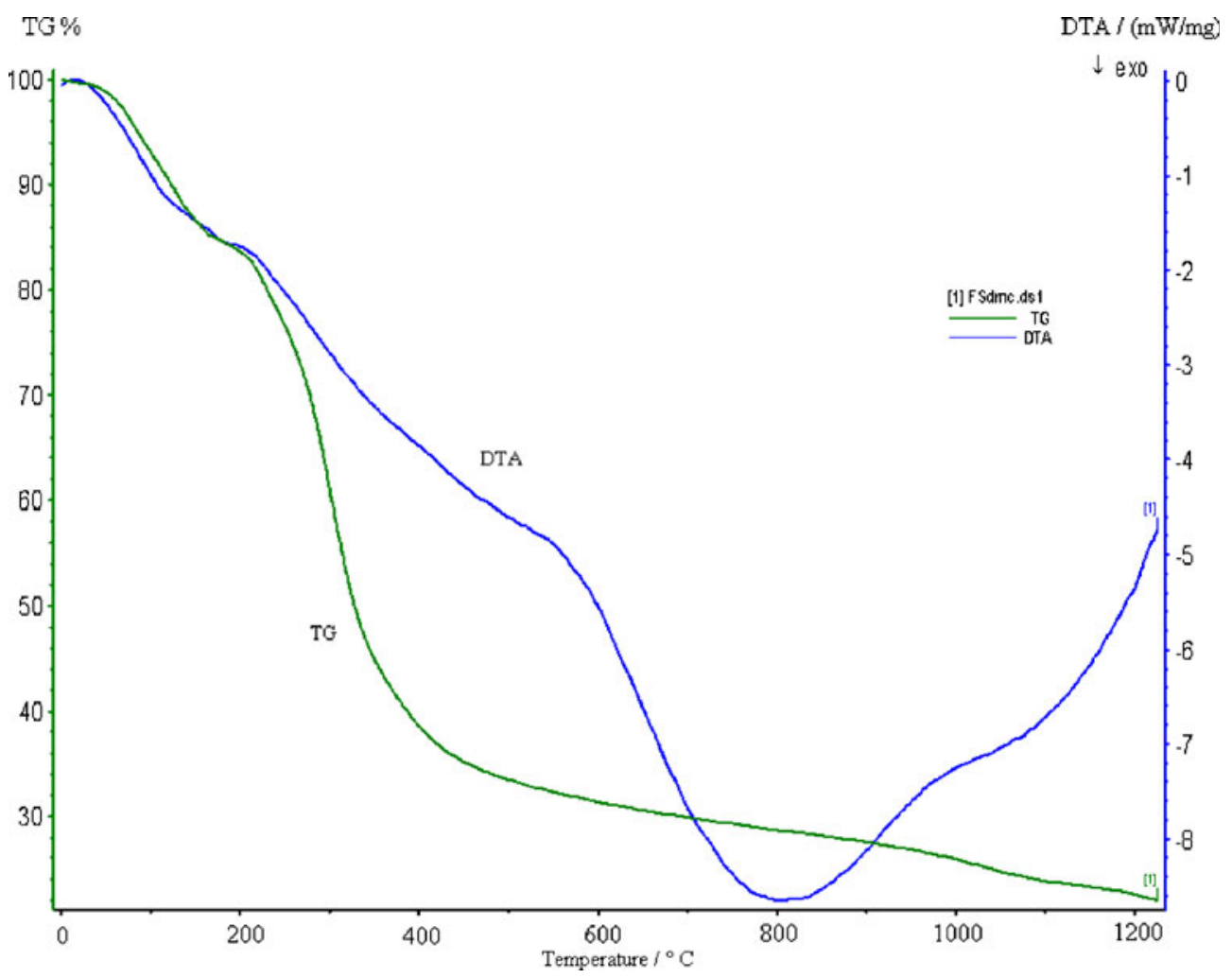

Figure 2. TG DTA of fish scale.

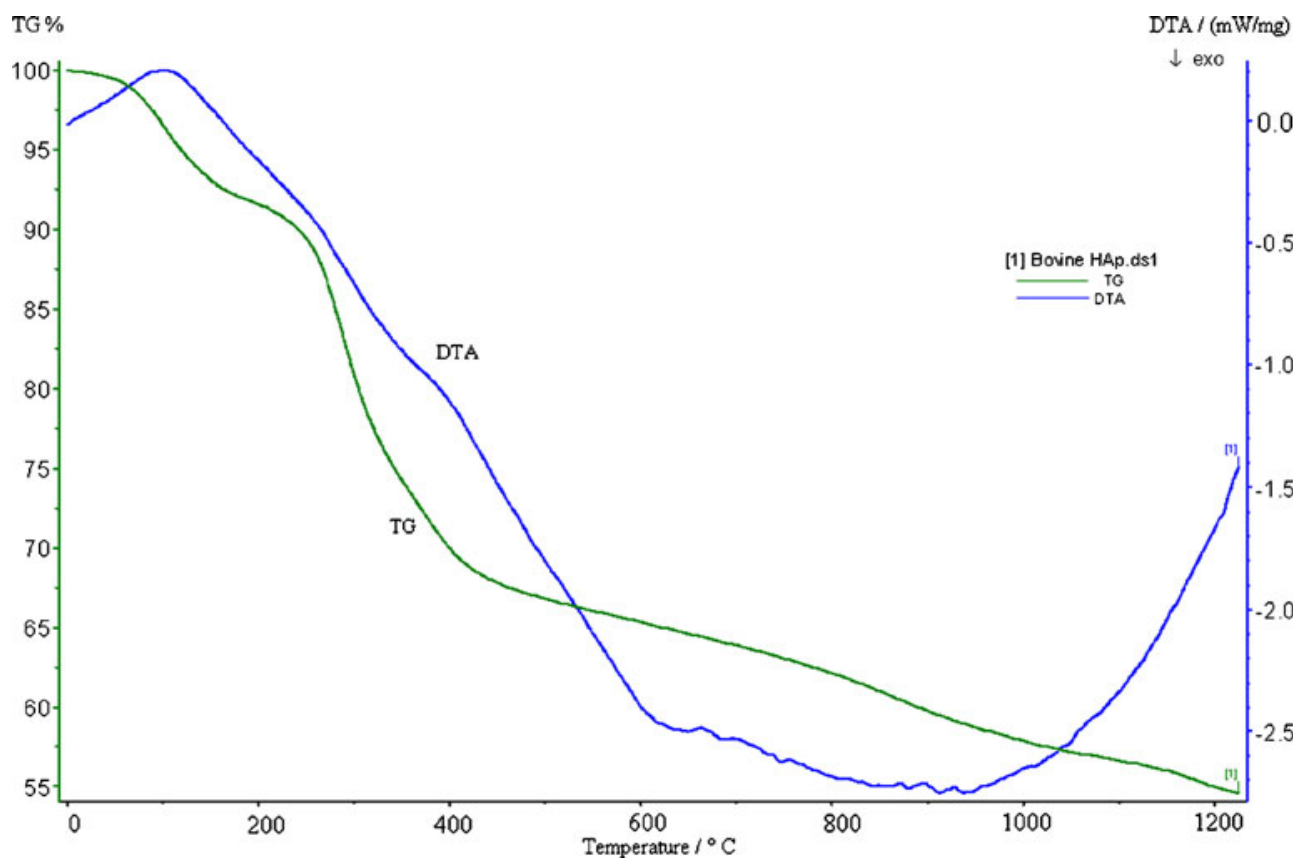

Figure 3. TG DTA of bovine bone. 
from egg shell, fish scales and cow bone, respectively. Identification of the phases was realized by comparing the experimental XRD pattern to standards complied by the International Centre for Diffraction Data (ICDD) using the cards 00-009-0432 for hexagonal HAp structure. Each pattern showed HAp as the only phase. Well resolved characteristic peak of highest intensity for HAp was obtained at a $2 \theta$ value of $31.77^{\circ}$ corresponding to 211 plane in all the cases. The phase formed is pure and matches well with standard pattern. Sharp peak intensity and well resolved peaks in XRD patterns of different synthesized powders proves complete crystallization.

The crystallite sizes of HAp particles were calculated using Scherrer's equation

$$
D=0.9 \lambda / B \cos \theta,
$$

where $D$ represents mean grain size, $B$ stands for full width at half maximum of the peak, $\lambda$ the diffraction wavelength $(0.154059 \mathrm{~nm})$ and $\theta$ the diffraction angle.

The Bragg reflection at (002) planes of HAp was considered to calculate the crystallite size. Table 2 shows crystallite size for HAp synthesized from egg shell, fish scales and bovine bone, respectively. It has been observed in all cases that HAp crystallite structure is predominant. From XRD characterization, the crystallite sizes of HAp synthesized from three different biosources minutely differed. However,

Table 1. Comparative mass loss study of HAp preparation from three different sources.

\begin{tabular}{lccc}
\hline $\begin{array}{l}\text { Temperature } \\
\text { range }\end{array}$ & $\begin{array}{c}\text { Egg shell } \\
\text { derieved HAp }\end{array}$ & Fish scale & $\begin{array}{c}\text { Bovine } \\
\text { bone }\end{array}$ \\
\hline $35-200^{\circ} \mathrm{C}$ & $-4.70 \%$ & $-14.54 \%$ & $-7.55 \%$ \\
$200-500^{\circ} \mathrm{C}$ & $-3.05 \%$ & $-50.79 \%$ & $-25 \%$ \\
$500-800^{\circ} \mathrm{C}$ & $-1.67 \%$ & $-5.20 \%$ & $-4.61 \%$ \\
$800-1100^{\circ} \mathrm{C}$ & $-0.69 \%$ & $-4.72 \%$ & $-5.67 \%$ \\
\hline
\end{tabular}

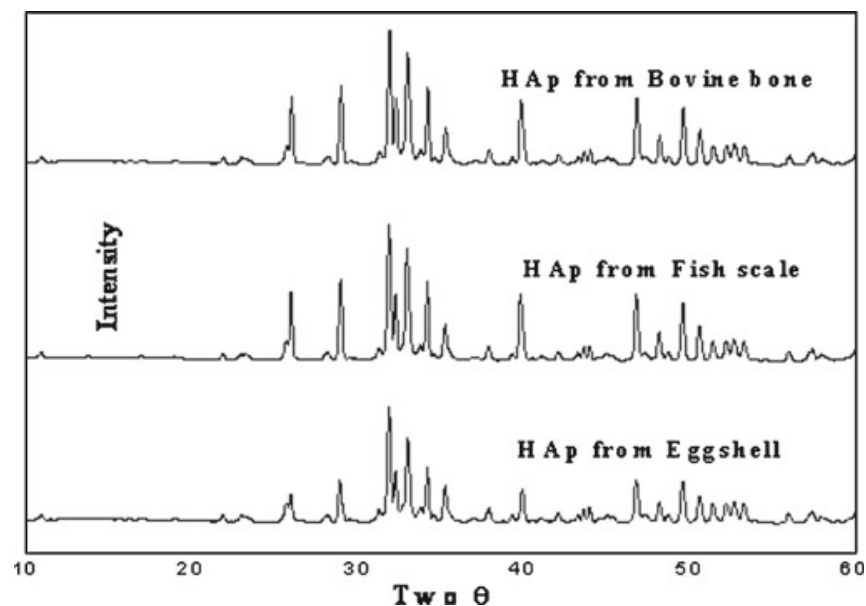

Figure 4. XRD pattern of HAp synthesized from egg shell, fish scale and bovine bone. some detailed investigations are required for finding out differences of preferred method.

\subsection{FTIR analysis}

Fourier transform infrared (FTIR) spectroscopy was employed to characterize different functional groups of hydroxyapatite $\mathrm{Ca}_{10}\left(\mathrm{PO}_{4}\right)_{6}(\mathrm{OH})_{2}$ (HAp) powder obtained from three biosources. Figure 5 shows FTIR spectrum of synthesized HAp from egg shell, fish scales and cow bone, respectively. The spectrum was recorded in the range of $4000-400 \mathrm{~cm}^{-1}$. The representative FTIR spectrum shows all characteristic absorption peaks of hydroxyapatite. The first indication for formation of hydroxyapatite is in the form of a strong complex broad FTIR band centred at about 1000$1100 \mathrm{~cm}^{-1}$ due to asymmetric stretching mode of vibration for $\mathrm{PO}_{4}$ group (Rocha et al 2007). The band at $576.30 \mathrm{~cm}^{-1}$ corresponds to $n 4$ symmetric $\mathrm{P}-\mathrm{O}$ stretching vibration of $\mathrm{PO}_{4}$ group (Varma and Babu 2005). As a major peak of phosphate group, the $n 3$ vibration peak could be identified in the region between 1100 and $960 \mathrm{~cm}^{-1}$ for all three powders which are due to $\mathrm{P}-\mathrm{O}$ asymmetric stretching of $\mathrm{PO}_{4}^{3-}$. The band at 2005-2079 $\mathrm{cm}^{-1}$ is due to overtone of $1040 \mathrm{~cm}^{-1}$ band. The presence of peak in the region $1400-1450 \mathrm{~cm}^{-1}$ was due to absorbed carbon dioxide. The crystalline powder

Table 2. Crystallite size of hydroxyapatite powder synthesized from egg shell, fish scale and bovine calcined at different temperatures.

\begin{tabular}{lcc} 
Serial no. & Natural source for HAp synthesis & Crystallite size \\
\hline 1. & Eggshell & $78.31 \mathrm{~nm}$ \\
2. & Fish scale & $75.36 \mathrm{~nm}$ \\
3. & Bovine bone & $77.32 \mathrm{~nm}$ \\
\hline
\end{tabular}

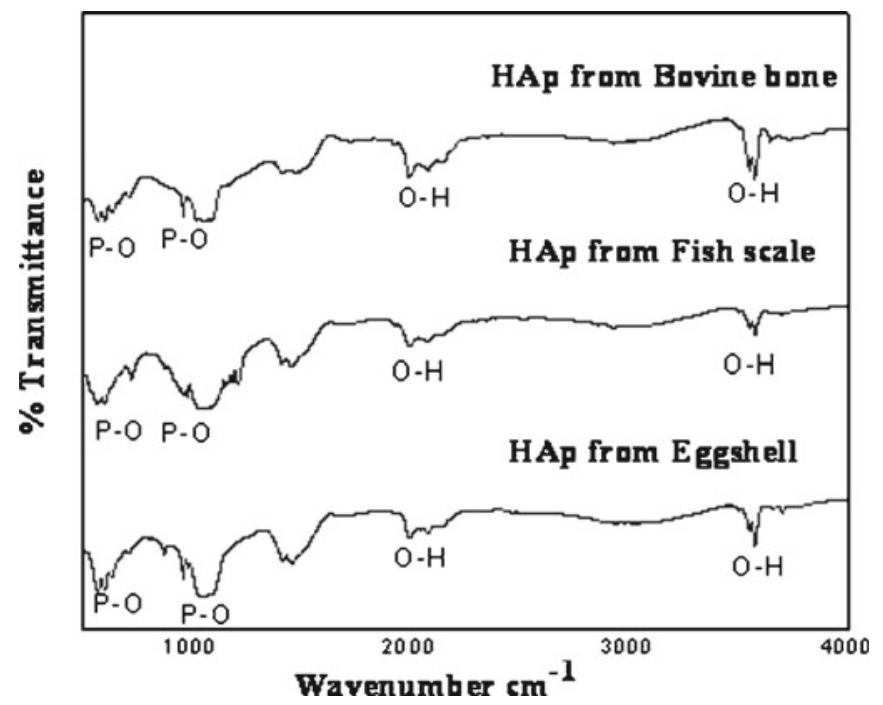

Figure 5. FTIR spectrum of hydroxyapatite powder synthesized from egg shell, fish scale and bovine bone. 


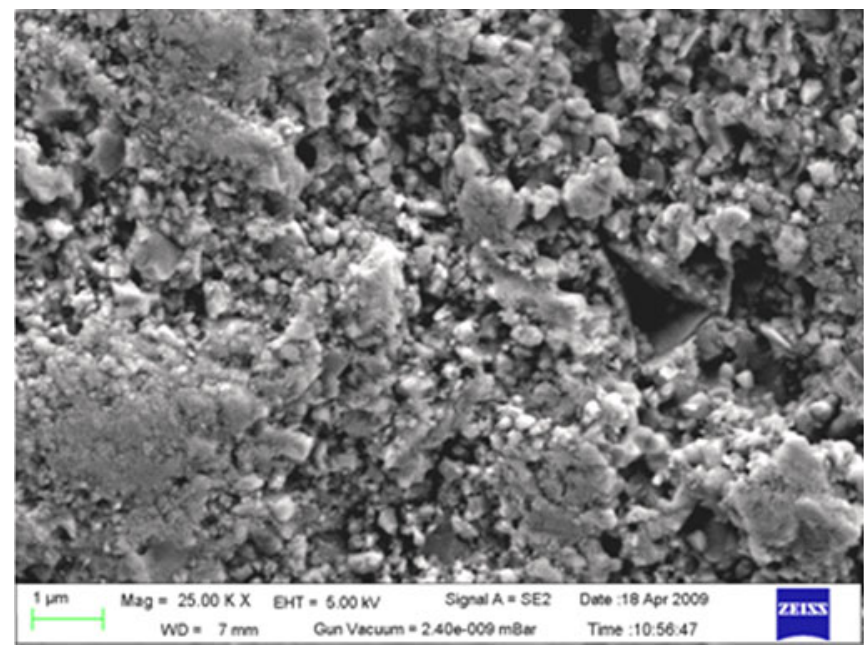

Figure 6. FE-SEM of HAp compact synthesized from eggshell.

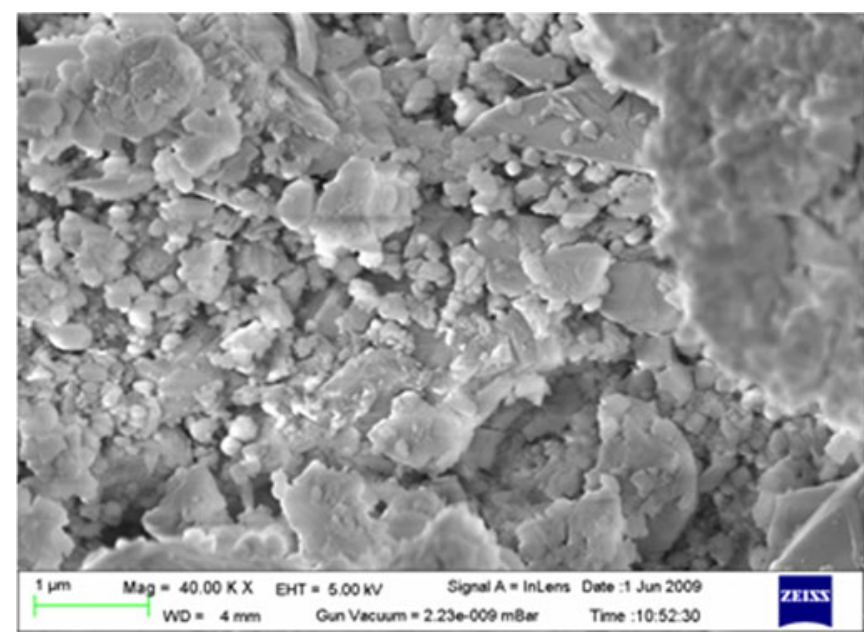

Figure 7. FE-SEM of HAp powder synthesized from fish scale.

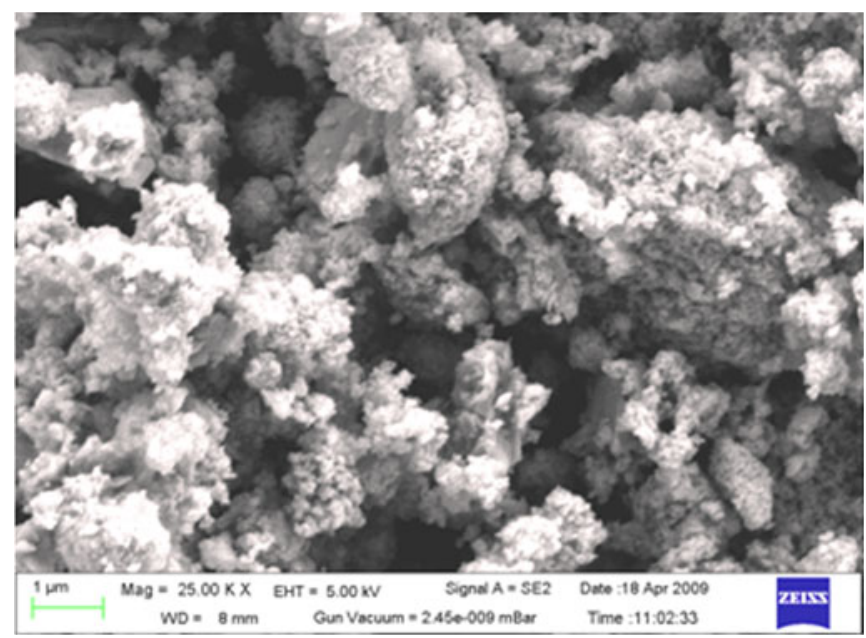

Figure 8. FE-SEM of HAp powder synthesized from bovine bone.

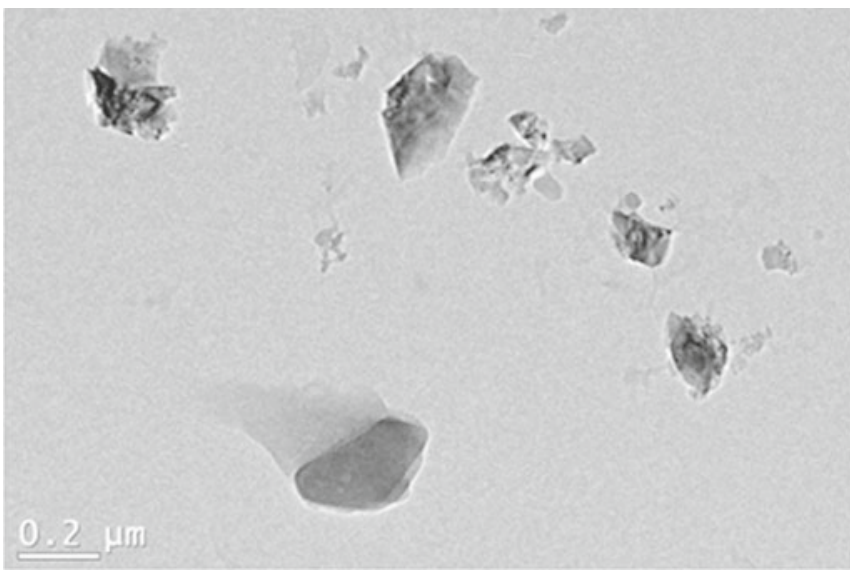

Figure 9. TEM of HAp synthesized from eggshell.

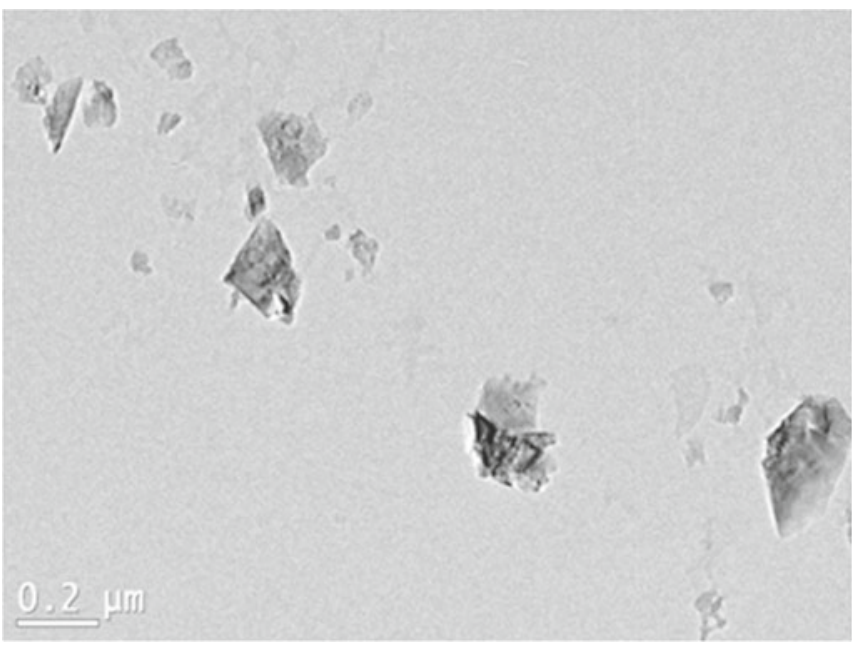

Figure 10. TEM of HAp compact synthesized from fish scale.

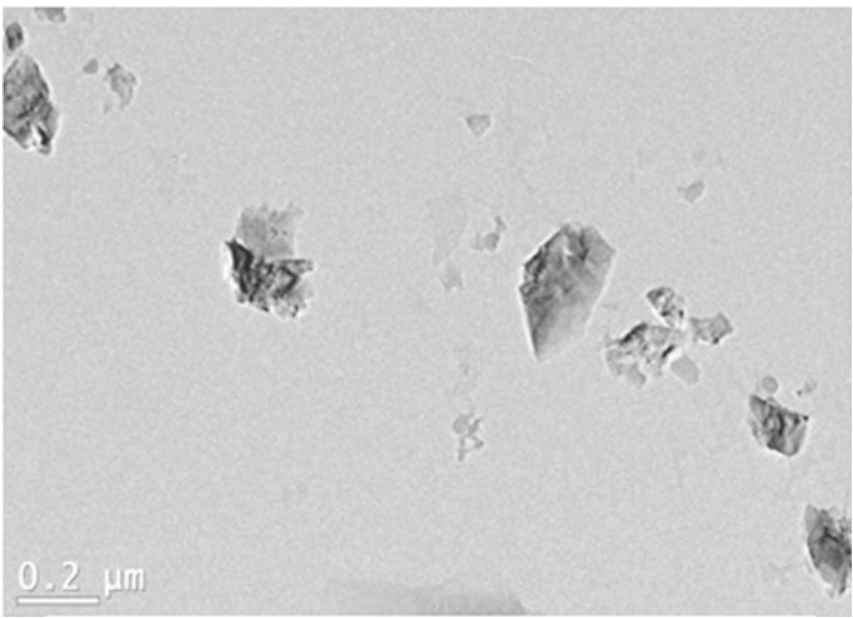

Figure 11. TEM of HAp synthesized from bovine bone. 


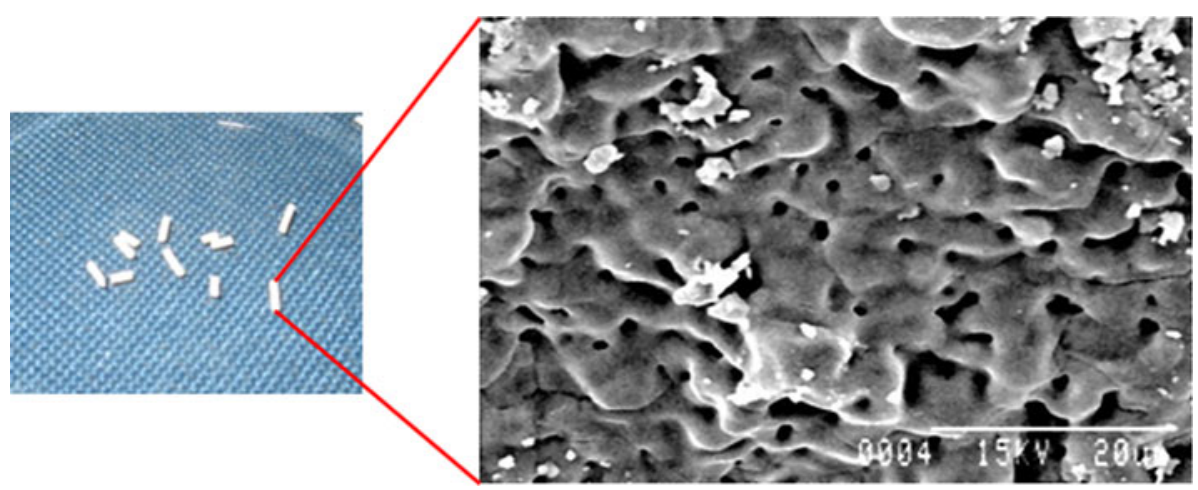

Figure 12. Bio fillers and SEM photomicrograph.

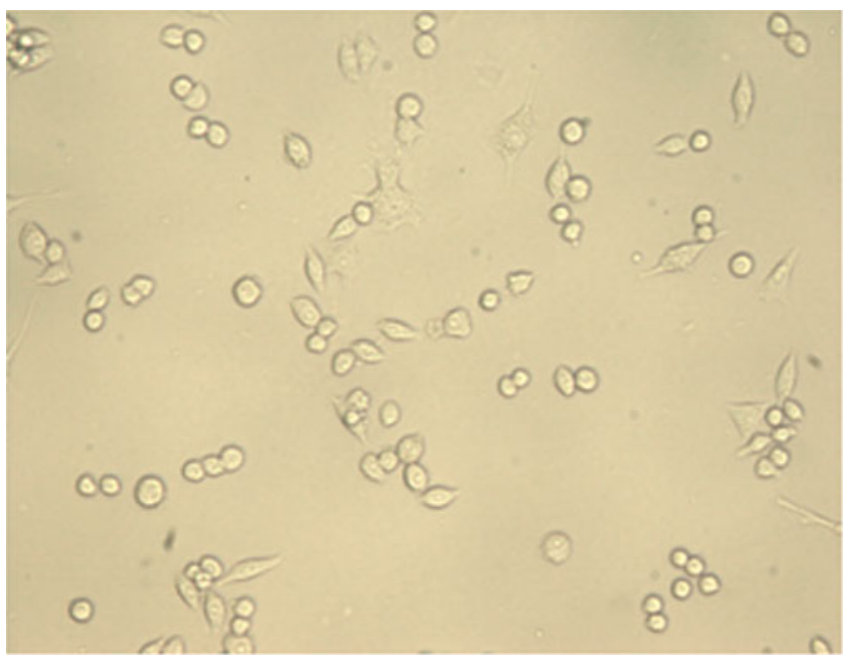

Figure 13. Control RAW cell media.

\section{Hydroxyapatite particles in RAW cell media}

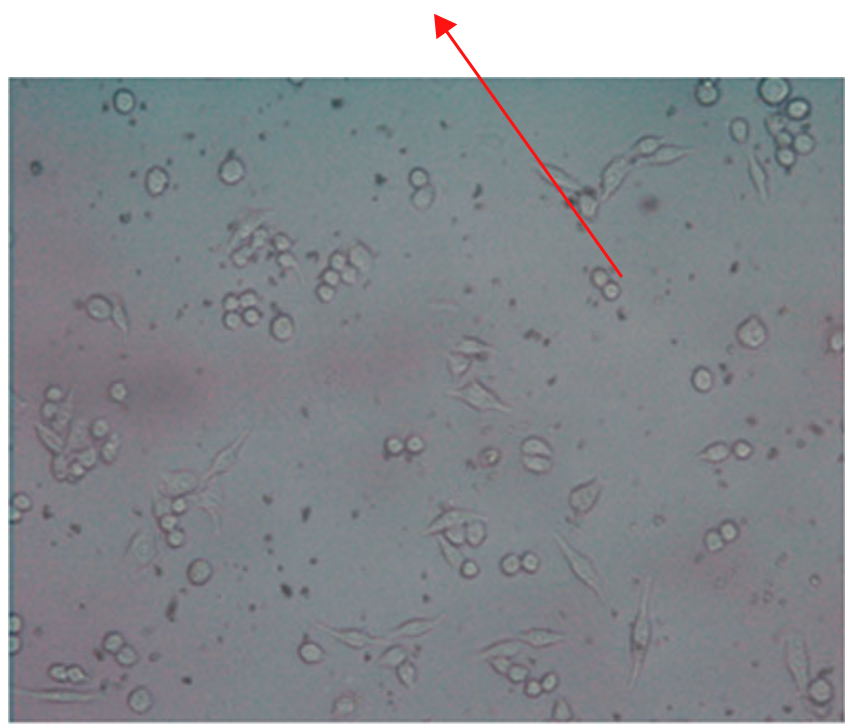

Figure 14. Eggshell derived hydroxyapatite particle in RAW cell media.

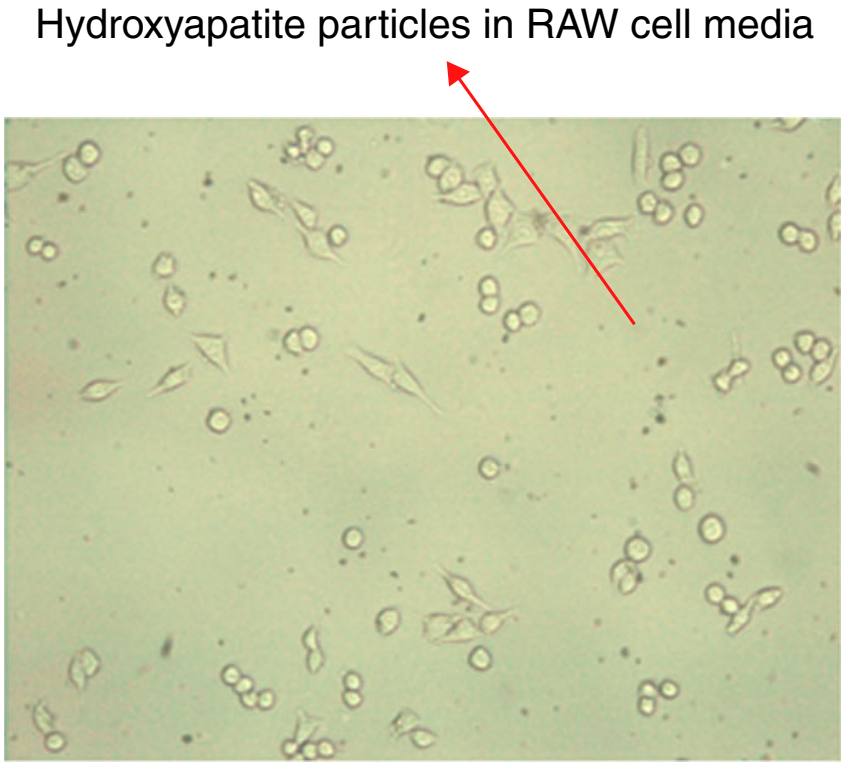

Figure 15. Fish scale derived hydroxyapatite particle in RAW cell media.

generates two characteristic stretching modes of $\mathrm{O}-\mathrm{H}$ bands at about $3497 \mathrm{~cm}^{-1}$ and $456 \mathrm{~cm}^{-1}$ which are noticed in all FTIR spectra of HAp.

\subsection{SEM analysis}

Figures 6-8 show SEM micrographs of hydroxyapatite samples. Images showed that biocompatible (Liao et al 1999) composites consisted of a highly porous network structure in the range between $15 \mu \mathrm{m}$ and $20 \mu \mathrm{m}$. SEM micrographs of synthesized HAp powder as depicted in figures 7 and 8 from egg shell, fish scale and bovine bone sources, respectively were soft agglomerated ultrafine HAp particles which break up easily during compaction due to high uniform pressure. All the samples show noticeable porosity.

$\mathrm{Ca} / \mathrm{P}$ ratio in all samples was closer to stoichiometric ratio of $\mathrm{Ca}$ and $\mathrm{P}(1.67)$ in the pure hydroxyapatite powder (Mostafa 2005) which again was confirmed through chemical determination. 


\subsection{TEM analysis}

TEM images show characteristics of synthesized HAp powder (figures 9-11) from egg shell, fish scale and bovine bone sources which also showed HAp were granular in shape with dimension of approximately $80-90 \mathrm{~nm}$ for these synthetic hydroxyapatite particle.

\subsection{Bio fillers made up of HAp powder}

The synthesized powder was wet ball milled for several hours and by using surfactants like Triton- $X$ small fillers were made for bio-implants. Figure 12 shows filler structure and

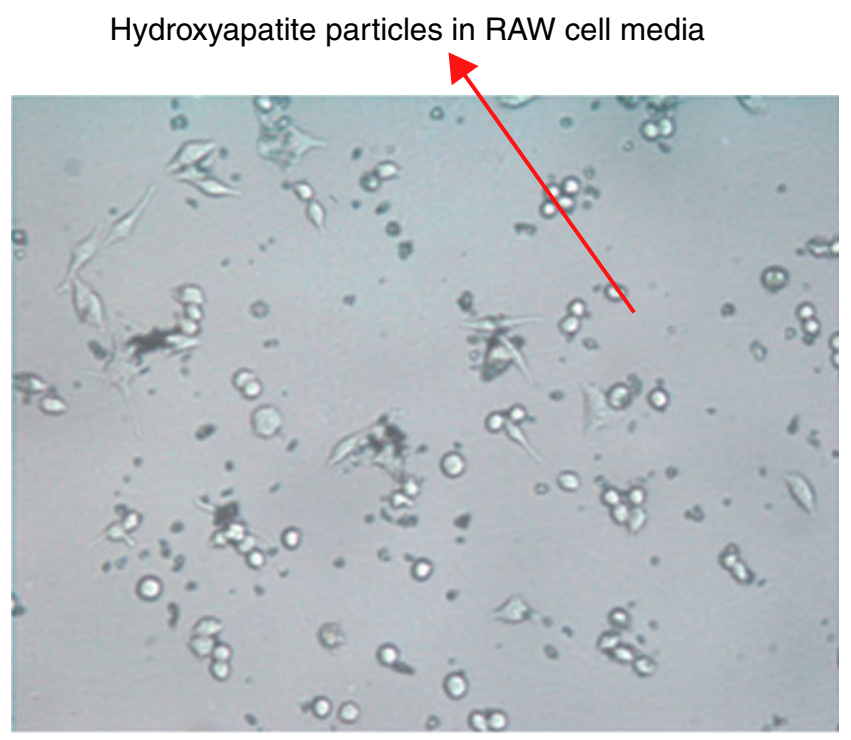

Figure 16. Bovine bone derived hydroxyapatite particle in RAW cell media. their SEM micrograph which reveals the porous structure. These small fillers were then heated up to $1200{ }^{\circ} \mathrm{C}$ temperature and prepared for in vivo bio-implantation and subsequent toxicity testing.

\subsection{In vitro analysis}

Hydroxyapatite powder samples as well as fillers and plates were utilized for further in vitro testing. First of all the samples are sterilized by autoclaving at $16 \mathrm{lb} / \mathrm{inch}^{2}$ pressure for 20 min. Then the samples were placed into an RPMI culture media. Here RAW cell lines were utilized for experimental purpose. Cell loads are given at $10^{5}$ cells/200 micro litre. After incubation in cell culture media samples are stained and observed under inverted microscopy. Figure 13 shows control cells attached in one of the 6 well plates culture vessels. Figures 14-16 show HAp particles incubated for $72 \mathrm{~h}$ along with macrophage like RAW cell lines. The cultured cells are stained with Trypan Blue and the result shows that there are no dead cells in the culture vessels. It confirms that there is no toxic effect of the synthesized HAp materials.

\subsection{Cell attachment}

Bio fillers are selected for in vitro cell attachment studies. Bio fillers are sterilized and then RAW cell lines are used in RPMI cell culture media for this study. After $72 \mathrm{~h}$ of incubation, samples cell culture media is decanted and washed thoroughly with PBS. After washing, 2\% paraformaldehyde solution were utilized for cellular fixation. Figure 17 shows SEM image of attached cells on the filler surface. This study reveals that cells can be attached on the hydroxyapatite surface which would be utilized as scaffold material for tissue engineering (Ikada 2006) application.

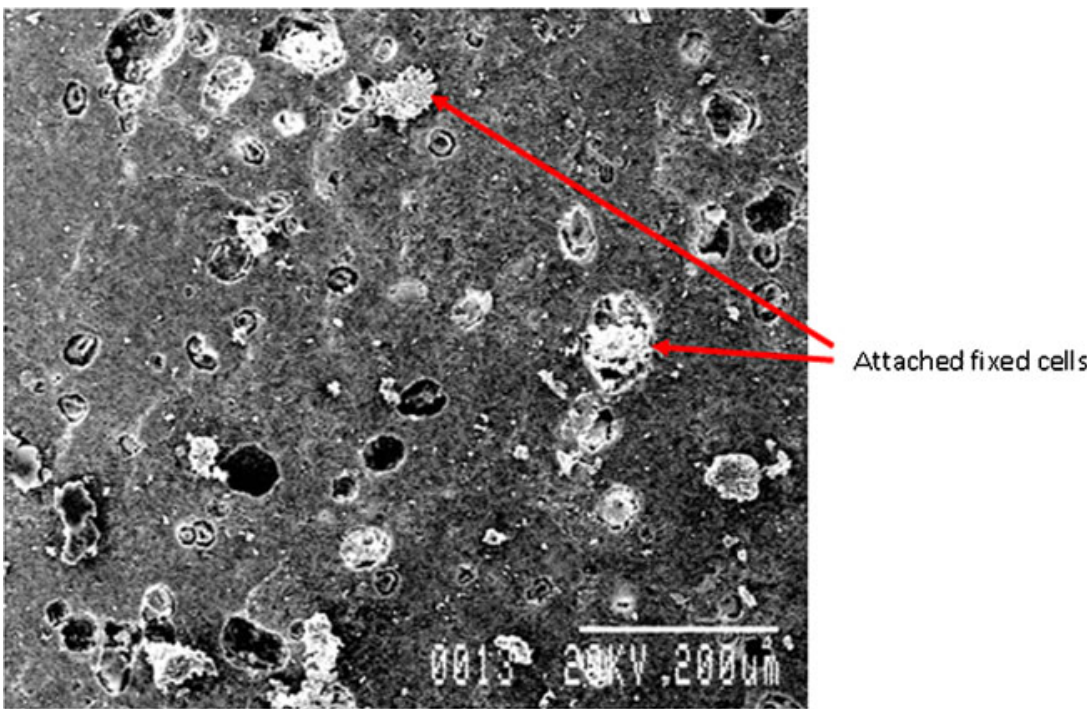

Figure 17. SEM image of attached cells at HAp surface. 


\section{Conclusions}

The present study reveals that hydroxyapatite powder can be synthesized by wet-chemical route and thermal decomposition using egg shell, fish scale and bovine bone in a cost effective way. FTIR and X-ray diffraction analyses indicated the phase purity and crystallinity of HAp powder. TGA analysis results showed thermal stability of HAp derived from three different biosources. The microstructural study of compacted powders show the presence of uniformly distributed very fine sub-micron particles. The SEM image of HAp ceramics prepared from these routes are found to exhibit 9-12\% porosity, which could be useful for biomedical applications as fillers or scaffold. TEM analysis showed HAp were granular in shape. The small biocompatible osteoconductive fillers appear to have great potential for bone tissue engineering as they showed no toxic effect on cell culture studies and also have good affinity of cellular attachment on the developed material surface. More systematic studies are required for in vivo, assessments of bio-ceramic composite scaffolds for bone tissue engineering.

\section{Acknowledgements}

The authors are grateful to CSIR, Govt. of India, for financial support through networking projects. The help rendered by our scientific \& technical staff of CSIR-CMERI, Durgapur, is also acknowledged. The authors are thankful to $\mathrm{Mr} \mathrm{P}$ Dhak, Mr A Paria and Mr B Das, Indian Institute of Technology, Kharagpur for thermal, FE-SEM and XRD analyses. The authors are also thankful to all the members of Infectious Diseases \& Immunology Division, Indian Institute of Chemical Biology, Kolkata, for cell culture study.

\section{References}

Bardhan R, Mahata S and Mondal B 2011 Adv. Appl. Ceram.: Struct. Funct. Bioceram. 11080

Balamurugan A, Kannan S and Rajeswari S 2002 Trends Biomater. Artif. Organs 1618

Fung Y C 1993 Biomechanics 500 (New York: Springer- Verlag Inc) Ikada Y 2006 J. R. Soc. Interface 3589

Kalita S J, Bhardwaj A and Bhatt H A 2007 Mater. Sci. Eng. C27 441

Kim W, Zhang Q and F Saito 2000 J. Mater. Sci. 355401

Liao C J, Lin F H, Chen K S and Sun J S 1999 Biomaterials 201807

Mobasherpour I, Heshajin M S, Kazemzadeh A and Zakeri M 2007 J. Alloys Compd $\mathbf{4 3 0} 330$

Mondal S, Mahata S, Kundu S and Mondal B 2010 Adv. Appl. Ceram.: Struct. Funct. Bioceram. 109234

Mortier A, Lemaitre J and Rouxhet P G 1989 Thermochim. Acta 143265

Mostafa N Y 2005 Mater. Chem. Phys. 95333

Ozawa M and Suzuki S 2002 J. Am. Ceram. Soc. 851315

Parthiban S P, Elayaraja K, Girija E K, Yokogawa Y, Kesavamoorthy R, Palanichamy M, Asokan K and Narayana Kalkura S 2009 J. Mater. Sci.: Mater. Med. 2077

Prabakaran K, Balamurugan A and Rajeswari S 2005 Bull. Mater. Sci. 28115

Rocha J H G, Lemos A F, Kannan S, Agathopoulos S and Ferreira J M F 2007 J. Mater. Chem. 155007

Roy M, Krishna B V, Bandyopadhya A and Bose S 2011 Acta Biomater. 7866

Sandeep G, Varma H K, Kumary T V, Babu S S and Annie J 2006 Trends Biomater. Artif. Organs 1999

Sankar S, Sekar S, Mohan R, Rani S, Sundarseelan J and Sastry T P 2008 Int. J. Biol. Macromol. 426

Tadic D and Epple M 2003 Biomaterials 244565

Van der Stok J, Lieshout E M M V, Massoudi Y E, Gerdine H, Van Kralingen G H V and Patka P 2011 Acta Biomater. 7739

Varma H K and Babu S 2005 Ceram. Int. 31109 